\title{
The Case Register, the Computer and the Cohort Study
}

\author{
Malcolm Cleverly, Computer Programmer, The Salford Case Registers and \\ John Cheadle, Research Fellow, Department of Community Medicine, University of Manchester
}

The Salford Psychiatric Case Register was started in its present form in 1968 and collected data on all persons coming into contact with the psychiatric services who were residents of the old County Borough which had a population of around 130,000 people. Since the reorganization of local authority boundaries, Salford has become a Metropolitan District, with twice the population and the Register has collected data on this new area since 1976.

The principle of a case register is that detailed information is collected on the inhabitants of a specific area where the population can be defined. It is most convenient if this area is one which the Census covers as an entity. In Salford the Health Authority and the Metropolitan District are contiguous and this makes it ideal for relating health statistics to the population as a whole. Although data are collected from over 12 sites, checks are made to be certain that all items of care are recorded for each individual, no matter where they are received. Conversely, a check is made to be sure that what appear to be new cases at one site, have not incepted elsewhere on an earlier occasion. To aid this process, and to maintain anonymity, each person is allotted a unique serial number. This number not only identifies the cases in a coded form but makes it very simple to do any sorting routines on the computer.

Because the population is defined and comes into a category for which the Census can provide detailed information, the number of people suffering from various complaints can be expressed as crude rates or proportions of that population. When necessary these rates can also be expressed in age or sex specific terms. People who are being treated within the area, but live outside it, are not included. Those residents who are cared for outside the area, however, are included. These are for the most part long-stay patients who were sent to outlying psychiatric hospitals in the 30s and 40s and are still alive.

The data are collected from all the caring agencies, hospitals, day centres, out-patient clinics, health centres, etc, by clerical staff specially employed and trained to do the job. All clinical and demographic data which are recorded in the notes are collected and updated when necessary.

All old cases have their follow-up added to their records so that their 'illness careers' are recorded in chronological order. These data include admissions to and discharges from hospital, with dates so that periods for these contacts can be calculated. Out-patient attendances (not appointments which might not have been kept), domiciliary visits and the number of injections of depot neuroleptics received from community psychiatric nurses or hospital departments are also recorded, as are suicide attempts, casualty and ward referrals, etc.
Care by community psychiatric nurses and social workers is recorded using a start date and an end date for the referral. This means that the number of days spent on the books can be calculated but not how many visits they received from these workers. The same applies to day care where patients are known to be on the books but can attend for differing numbers of days each week.

\section{Cohort analysis and its uses}

The well established case register, with its immense amount of data collected on thousands of individuals, is the ideal medium for cohort studies.

Originally the word cohort was used to describe a group of people born on the same day in some well defined population. The term is now used in a much broader sense and can be defined as 'those people within a geographically or otherwise delineated population who experienced the same significant life event within a given period of time' (Glenn, 1977). The period, population and life event must be specified as conventionally it might be assumed that, without specification, a birth cohort was implied. If the population, in the statistical sense, is small and the experience, unlike birth, a rare one, it may be necessary to extend the period to months or even years in order to find enough cases, but the principle remains the same. The term has therefore been broadened to include groups of people who share some social, clinical, demographic or environmental characteristic or a combination of these characteristics. The group is then followed up, prospectively, and the events of interest studied, such as the incidence of a particular disease. These studies can be expensive and a great deal of time is required before any results become available. When using a case register all the events which are to be studied have already been recorded including the outcome, if there is one. These studies are therefore retrospective, although it is possible to simulate a prospective study in that you can study groups from one year to the next up to the present. In psychiatry the case register and the technique of studying cohorts can be of immense value for studying patterns of care, which have already been formed, over long periods.

A special computer programme has been developed to select cohorts from the main body of the case register. A simple flow chart for this can be seen in Fig. 1. The search criteria specify the characteristics which make up the cohorts. It selects the first cohort and records all relevant data on each case, including the number and lengths of contacts with psychiatric services received during one complete year after entering it. Whilst selecting and collecting data on any subsequent cohorts, it collects the data for 


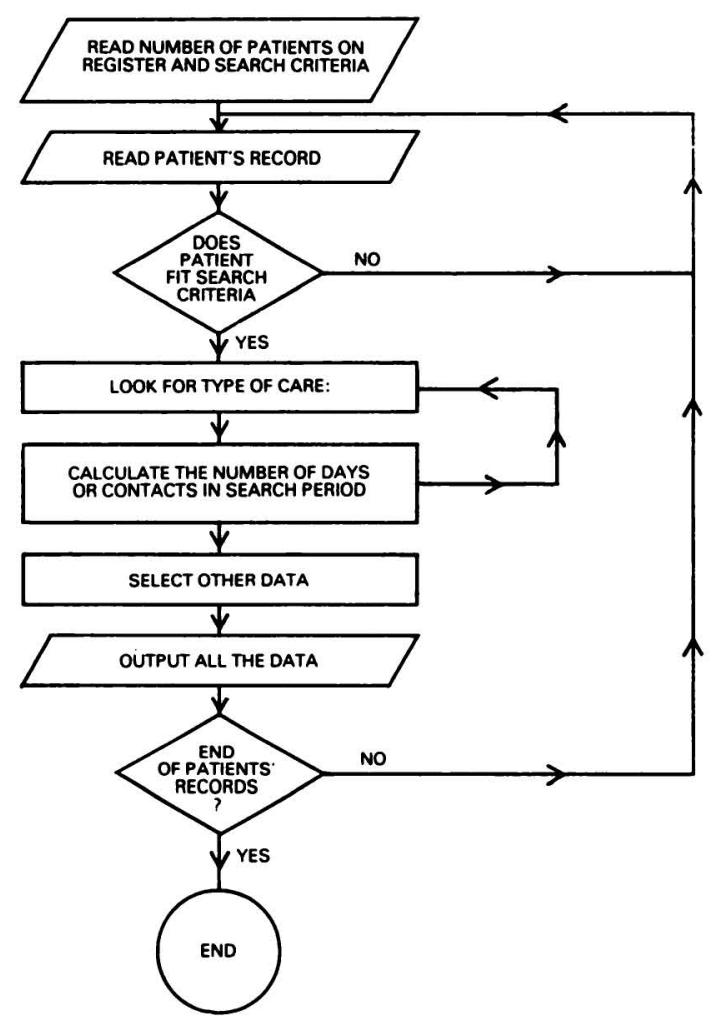

Fig. 1. Flowchart of the cohort analysis programme.

that year on all those previously selected. The result is a series of printouts, one for each year studied, containing demographic and clinical data for that year on all relevant patients, as well as a record of all their service use during that year. This information is stored in a computer file and accessed for analysis, using the Statistical Package for Social Scientists (Nie et al. 1975).

Various contacts, or treatments, are searched for in the programme using a loop. These are, hospital admissions and discharges, the start of episodes of day-care and their end, all out-patient appointments, injections of depot neuroleptics, days on the books of social workers and days on the books of community psychiatric nurses. Deaths or outward migration are recorded in the year in which they happen, but the cases still remain on all future searches with blanks in the treatment columns. If someone merely receives no treatment the treatment columns are filled with zeros. All the demographic details such as age, sex and marital status are also listed, as is the current diagnosis.

With case register data going back to 1968 it is possible to select cohorts from the early years and look at the patterns of their contacts up to the present. This enables us to distinguish between heavy and light users of the services and to search for items of data which are associated with or might account for the various degrees of service use. Conversely, those with serious, non-remitting, diagnoses might be expected to remain in some form of contact. If this does not appear to be the case we can investigate these groups in order to find out who is in fact caring for them outside the usual psychiatric services which are monitored by the register. This kind of retrospective study can be continued prospectively in the light of the findings.

We have, for example, looked at a series of cohorts comprising people who have become mentally ill for the first time whilst aged 65 or over. It was possible to follow most of these cohorts up for at least six years and the earliest now has 15 years' of data. Another study looks at cohorts of people incepting with schizophrenia, but any criteria can be set and any group studied, not only cohorts.

As the subjects are followed up for a complete twelvemonth period from the date of their entry, this means that those who enter during one calendar year will be followed up for the rest of it and part of the next. They will not share the same calendar period, but will share a period that is common to the rest of the cohort starting with the contact with the services. This means that we can ask what has happened to these people by the time they have been in contact for a year, two years, etc. We can look at the amount of treatment each has received in these equal periods since inception and compare the different diagnoses on this parameter. We can also look at death rates, admission rates and rates for any other contacts stored on the Register. All these data lend themselves to producing life-tables quite easily. One disadvantage is that we cannot reliably look at recovery rates. We can be reasonably sure that patients are out of contact with the services, but we cannot be sure why. They might be under the care of another agency. This is a particular problem with the elderly as they might enter old folk's homes which are not monitored by the Register or they might have migrated to another district not covered by the Register. This group does, however, highlight the need for research in this area, and the size of the group is easily determined from the data on hand.

There is no reason why cohorts should not be selected on any criteria if programming time and expertise is available. If a series of cohorts is studied and their members followed up to the present, it becomes a simple matter to sort the complete file into serial number order. This means that all the yearly contacts for the same patient will be together in the file and therefore their complete history is easy to access.

We now have versions which will select samples by several variables or will process a list of serial numbers selected on criteria which are not recorded on the register but which become known to us through field work. Many patients attend community day centres which are not part of the psychiatric services and are not therefore monitored by the Register. When these have been discovered as a result of 
field work it is a simple matter to look at their histories in the manner described above.

Patterns of care can be of value when considering prognosis for groups of patients or individual cases. The amount of service use generated over a long period by these groups is of use in planning the services. We believe that we have a useful contribution to make in both these fields with the development of the techniques we have described.
ACKNOWLEDGEMENTS

The Salford Case Registers are maintained on computer by a grant from the DHSS and the facilities are provided by the University of Manchester Regional Computer Centre.

\section{REFERENCES}

GLENN, N. D. (1977) Cohort Analysis. Beverly Hills: Sage.

Nie, N. H., Hull, C. H., Jenkins, J. G., Steinbrenner, K. \& BeNt, D. H. (1975) Statistical Package for Social Scientists (2nd Edition). New York: McGraw-Hill.

\section{Parliamentary News \\ (April 1983-July 1983: Part II)}

\section{Law of Incest (Scotland)}

In reply to a question, the Scottish Secretary said (14 April 1983) that the Government had received the report of the Scottish Law Commission on Incest and some comments about it, but they had no immediate plans for legislation on the subject. They thought it might more appropriately be considered in the context of a Private Member's Bill.

\section{Police and Criminal Evidence Bill}

The Police and Criminal Evidence Bill, which was passing through the last Parliament, was eventually abandoned and is likely to be reintroduced. However, it is of note that in response to pressure from many organizations including the Royal College of Psychiatrists, the then Home Secretary, Mr Whitelaw, agreed to bring forward Amendments to provide that confidential personal records relating to the work of medical and other caring professions and their voluntary counterparts and other voluntary counselling agencies should be altogether exempt from the provisions of Clause 10 which was designed to allow the police, when investigating serious crime, to obtain access to evidence of such crime for use in criminal proceedings.

\section{Solvent Abuse (Scotland) Act 1983}

This Act, which started its life as a Ten-Minute Bill, received the Royal Assent on 13 May 1983. Only about fifteen such Bills have been successful since 1945. The Act is the first statutory recognition of solvent abuse as a major problem, but it applies only to Scotland. It makes solvent abuse a ground for referral to a children's panel to which, in Scotland, young people under the age of 16 may be referred for, among other things, care and protection, guidance and treatment. The panels operate under the Social Work (Scotland) Act 1968, and problems can be discussed in informal surroundings with parents in attendance. The Act does not refer to adults.

\section{Psychogeriatric facilities \\ Wales}

On 25 April $1983 \mathrm{Mr}$ Wyn Roberts indicated in a written reply that almost all health authorities make in-patient provision for psychogeriatric patients, but only Gwent and MidGlamorgan authorities designate beds for this purpose. In September 1982 the average number of available beds was 262 and 26 respectively within these authorities.

\section{England}

On 21 April 1983, in a written reply, Mr Finsberg said that national statistics do not provide this information.

\section{Scotland}

On 21 April 1983, Mr John MacKay for the Scottish Office said that some facilities for the care of psychogeriatric patients are designated, but the majority of elderly patients are treated in mental illness beds and figures are not collected to identify the specific number of beds used for psychogeriatric purposes. The majority of patients resident in mental hospitals or psychiatric units in Scotland are over 65 years old.

\section{Resource assumptions for the NHS}

On 30 June $1983 \mathrm{Mr}$ Fowler indicated the longer term revenue and capital assumptions as a basis for NHS planning. He said they were intended as a guide for the next ten years and by replacing the unrealistic ones issued in 1978 would enable health authorities to plan ahead with more confidence. The future levels of resources for health services will depend on the success of the national economy and other demands, but he had told health authorities to assume for planning purposes that resources for hospital and community health services could grow at the rate of around 0.5 per cent a year. He said that this was not a commitment and 